\title{
127. A New Living Coral, Pseudosiderastrea tayamai, from Dobo in Wamar, Aru Islands.*
}

\author{
By Hisakatsu YaBe and Toshio Sugiyama. \\ (Comm. by H. YABE, M.I.A., Nov. 12, 1935.)
}

In the latest occasion of his repeated voyages among the South Sea Islands to study coral reefs and islands, Mr. R. Tayama of our Institute of Geology and Palaeontology, Sendai, landed on Dobo in Wamar, Aru Islands ( $5^{\circ} 44^{\prime}$ S. lat., $134^{\circ} 13^{\prime} \mathrm{E}$. long.) on board Zuihômaru of the Fisheries Experimental Station of the South Sea Office and spent several days of the last September (1934). Among the specimens of reef-corals collected by him from the island we have distinguished the following sixteen species in sixteen genera: Galaxea clavus (Dana), Cyphastrea microphthalma (Lam.), Orbicella cfr. curta Dana, Favia speciosa (Dana), Favites abdita (Ell. \& Sol.), Goniastrea cfr. retiformis (Lam.), Oulophyllia? sp., Symphyllia? sp., Lobophyllia corymbosa (Forskål), Maeandra lamellina Ehr., Pseudosiderastrea tayamai gen. et sp. nov., Pachyseris rugosa (Lam.), Goniopora sp., Astraeopora sp., Montipora verrucosa (Lam.), Porites efr. australiensis Vaughan. All but one of these specifically determined forms are those not only thriving almost everywhere in the tropical seas, but also found living in the Japanese seas; the exception being Pseudosiderastrea tayamai to be briefly described below.

The new form now under consideration is represented by a small, but complete specimen, which in its general aspect is very similar to Siderastrea from the Atlantic. This genus erected by de Blainville in 1830 on Madrepora radians Pallas has many other living species and all of them are confined in their distribution to the Atlantic. The present material examined in detailed comparison with Siderastrea radians and S. siderea (Ell. \& Sol.) in the possession of our Institute differs from them at least in one important feature to warrant its generic separation from Siderastrea.

Pseudosiderastrea nov. gen.

Genotype: Pseudosiderastrea tayamai, sp. nov. from Aru Islands. Monotypic at present.

Pseudosiderastrea tayamai sp. nov.

(Text-figs. 1-5)

Corallum encrusting, thin, with slightly convex upper surface; oblong in outline, $70 \mathrm{~mm}$. in longer diameter; about $8 \mathrm{~mm}$. thick at center, somewhat thinner along periphery. Epitheca absent? Calices

* We are most grateful to the Imperial Academy for the financial support given to our studies on reef-bilding corals. 
subequal, polygonal, usually pentagonal or hexagonal, $5 \mathrm{~mm}$. or a trifle less broad; rather shallow, straight upper margin of septa grudually descending from very narrow, but distinct wall to narrow axial fossa around columella; wall appearing as narrow and never prominent crest between calices. Septa not prominent, solid, not perforated ; $30-45$ in number arranged in 4 cycles. Septa of first and second cycles subequal, extending to columella, those of later cycles confluent along their inner margin by means of synapticulae to adjacent one of next earlier

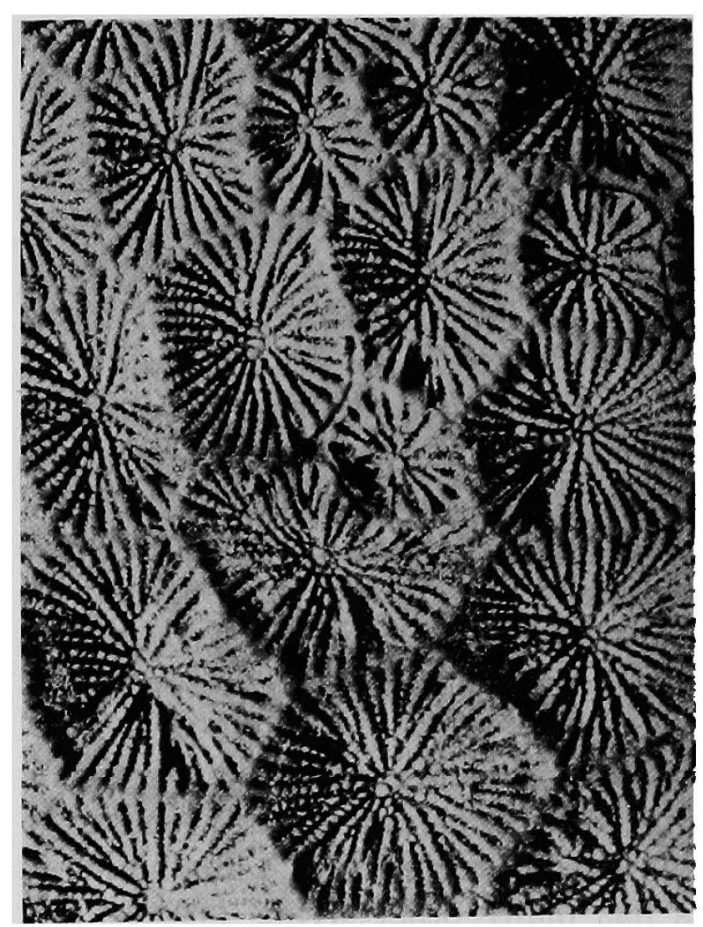

2

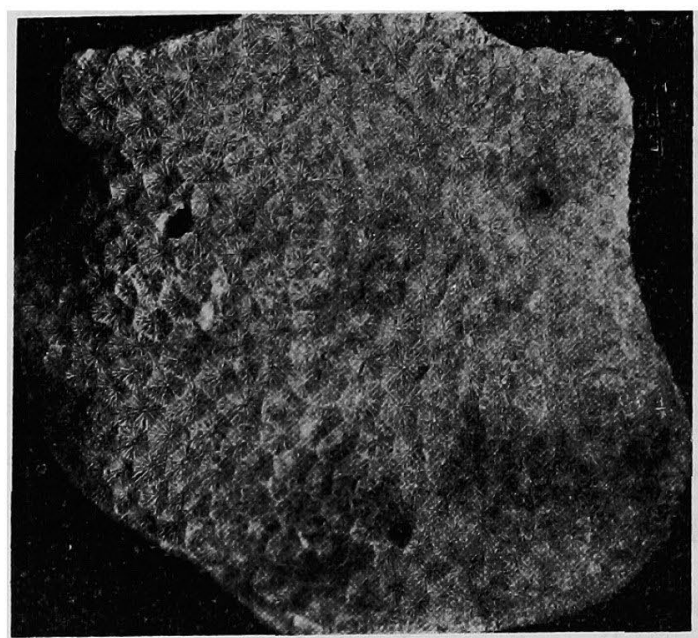

1

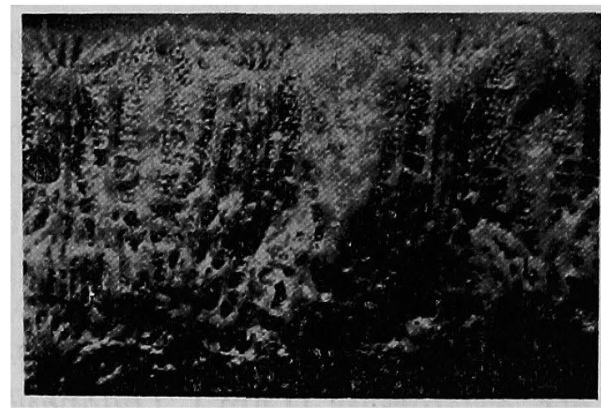

3

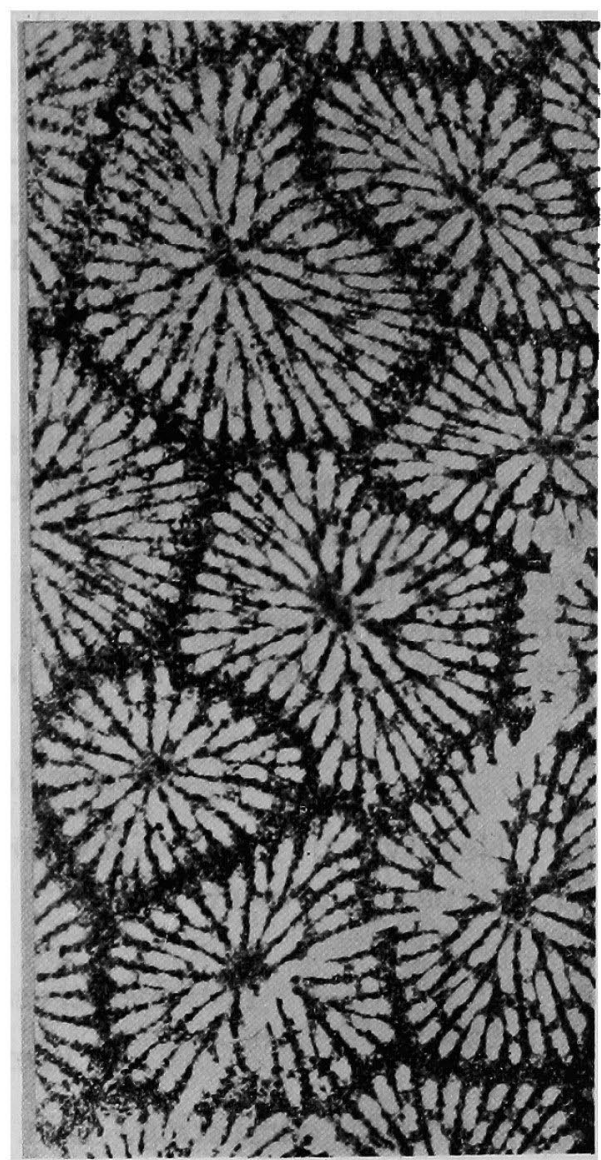

4

Fig. 1. Upper surface. $\times 1$.

Fig. 2. A part of the same, enlarged. $\times 5$.

Fig. 3. Vertically fractured face of the specimen shown in Fig. $1 . \quad \times 5$.

Fig. 4. Tangential section of the same specimen. $\times 9$. 


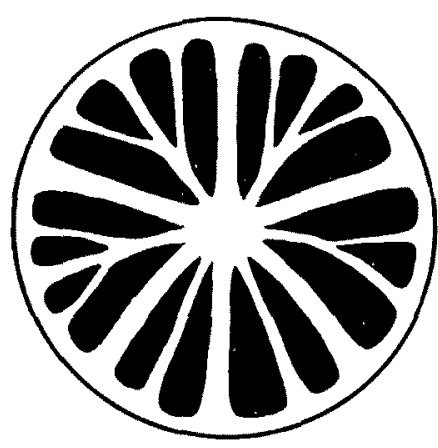

5

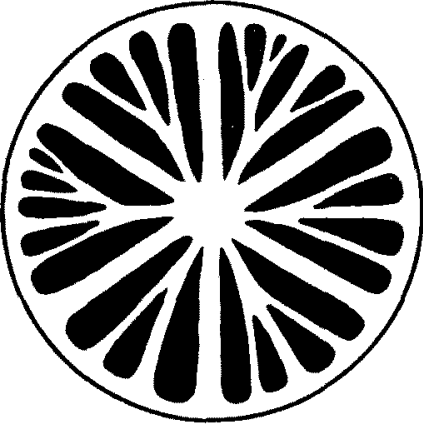

6

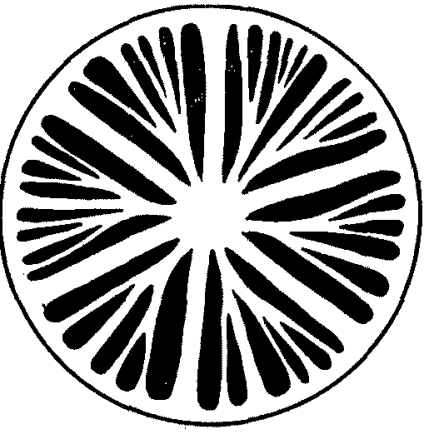

7

Fig. 5-7. Diagramatic figures illustrating the manner of septa.

cycles; margin conspicuously dentate or granulate, each granule corresponding to end of a trabecula ; lateral faces with very minute granules (occasionally obscure) arranged in oblique rows running downward to wall. Columella small, not much prominent, papillary, consisting of a number of ascending trabecula which often fuse together at places. Synapticulae well and dissepiments better developed, latter arranged nearly parallel and about 10 counted in $5 \mathrm{~mm}$. Growth by intercalicinal budding.

Remarks : The present form is more closely related to Siderastrea than to any other corals hitherto known as stated above, both certainly agreeing with each other in the arrangement of septa, form of septal denticles, granulation of septal faces, papillary columella, and mode of growth. The essential differences recognizable between them, however, lies in the absence of the minute pores traversing septa in our form and their presence in Siderastrea. Moreover, though both dissepiments and synapticles are well developed in the two forms, yet the former are more and the latter less numerous and distinct in ours than in Siderastrea.

Another coral with very similar features is Anomastraea irregularis Marenzeller ${ }^{1)}$ on which Emile von Marenzeller initiated the genus Anomastraea in 1901 ; this has minutely perforated septa and is thus easily distinguished from ours with solid septa. Moreover, the septal denticles become gradually larger toward the center of calices and the innermost ones often build a pali-like structure around the columella in the African form, while such tendency does not exist in ours; further, according to Marenzeller, Anomastraea is characterized by its inter- and intracalicinal gemmation.

Locality: Dobo in Wamar, Aru Islands; Rec. Reg. No. 56525.

1) E. von Marenzeller: Ostafrikanische Steinkorallen. Mitt. Naturh. Mus. Hamburg. Jahrg. 1901, p. 124. 